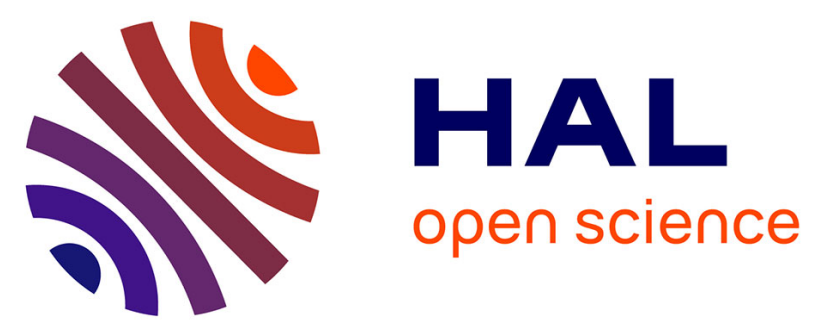

\title{
Advanced colonic cancer with clinically suspected bladder invasion: Outcomes and prognosis from a multicentric study of 117 patients from the FRENCH research group
}

Cindy Vuillermet, Hélène Meillat, Gilles Manceau, Ben Creavin, Clarisse Eveno, Stéphane Benoist, Yann Parc, Jérémie Lefèvre, Sara Arfa, Paul-Noël Dumont, et al.

\section{- To cite this version:}

Cindy Vuillermet, Hélène Meillat, Gilles Manceau, Ben Creavin, Clarisse Eveno, et al.. Advanced colonic cancer with clinically suspected bladder invasion: Outcomes and prognosis from a multicentric study of 117 patients from the FRENCH research group. Surgery, 2020, 168 (5), pp.786-792. 10.1016/j.surg.2020.06.021 . hal-03024923

\section{HAL Id: hal-03024923 \\ https: / hal.sorbonne-universite.fr/hal-03024923}

Submitted on 26 Nov 2020

HAL is a multi-disciplinary open access archive for the deposit and dissemination of scientific research documents, whether they are published or not. The documents may come from teaching and research institutions in France or abroad, or from public or private research centers.
L'archive ouverte pluridisciplinaire HAL, est destinée au dépôt et à la diffusion de documents scientifiques de niveau recherche, publiés ou non, émanant des établissements d'enseignement et de recherche français ou étrangers, des laboratoires publics ou privés. 


\section{Surgery}

\section{Advanced colonic cancer with clinically suspected bladder invasion: outcomes and prognosis from a multicentric study of 117 patients from the FRENCH research group. --Manuscript Draft--}

\begin{tabular}{|c|c|}
\hline Manuscript Number: & 20200270R1 \\
\hline Article Type: & Original Communication \\
\hline Section/Category: & Clinical \\
\hline Keywords: & $\begin{array}{l}\text { Locally advanced colon cancer; bladder invasion; local recurrence; urinary tract } \\
\text { involvement; enbloc resection }\end{array}$ \\
\hline Corresponding Author: & $\begin{array}{l}\text { jeremie H lefevre, MD, PhD } \\
\text { Hôpital Saint-antoine } \\
\text { Paris, FRANCE }\end{array}$ \\
\hline First Author: & Cindy Vuillermet \\
\hline \multirow[t]{8}{*}{ Order of Authors: } & Cindy Vuillermet \\
\hline & Hélène Meillat \\
\hline & Gilles Manceau \\
\hline & Ben Creavin \\
\hline & Clarisse Eveno \\
\hline & Stéphane Benoist \\
\hline & Yann Parc \\
\hline & jeremie $\mathrm{H}$ lefevre, MD, PhD \\
\hline Manuscript Region of Origin: & FRANCE \\
\hline Abstract: & 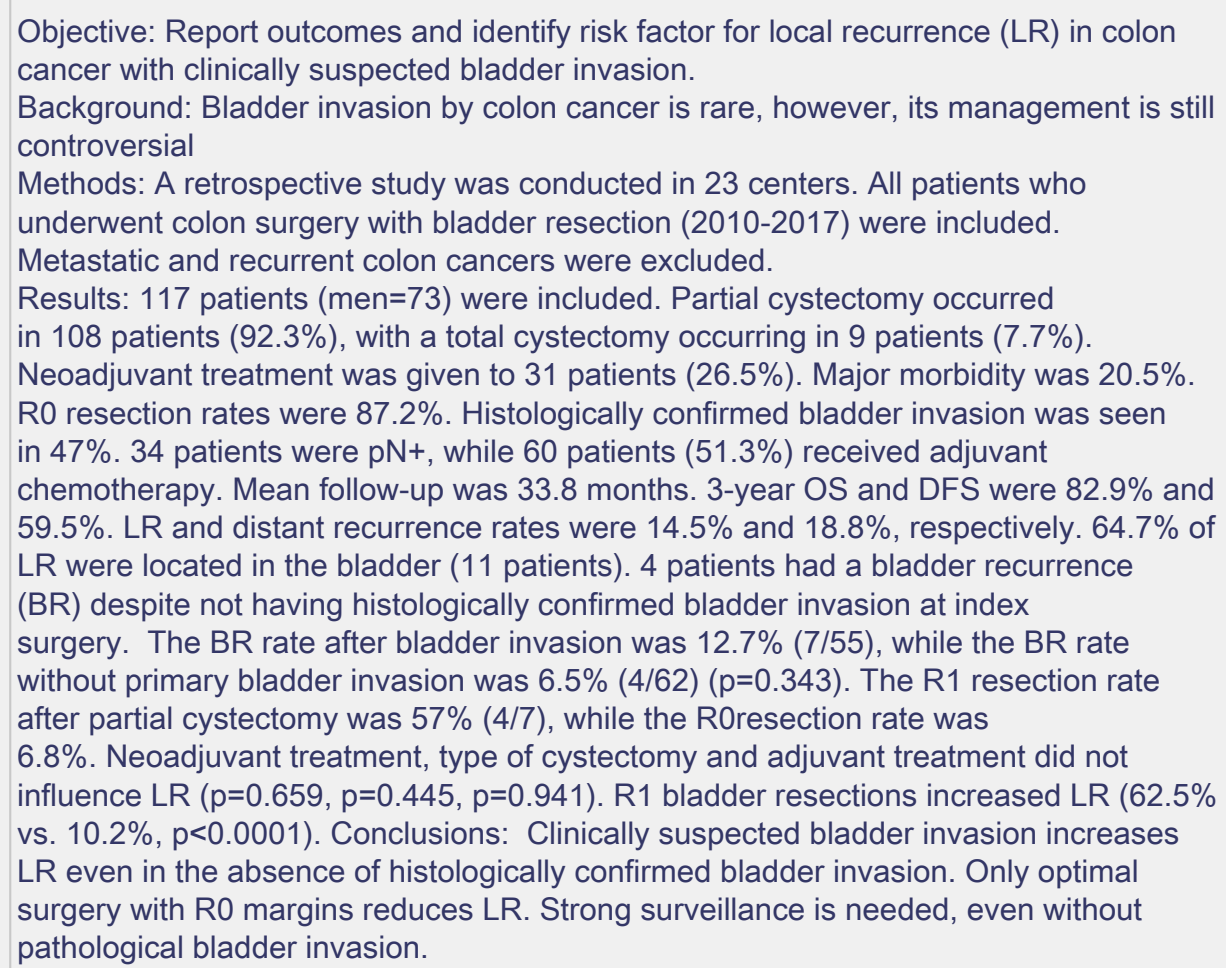 \\
\hline
\end{tabular}


To the Editor-in-Chief

Dear Sir,

Please find attached the revised manuscript submission entitled "Advanced colon cancer

with clinical bladder invasion: outcomes and prognosis from a multicentric study of 117

patients from the FRENCH research group.” (Surgery RE: 20200270)

We have been paying much attention to all the points raised by the reviewers and we have responded to them separately, with some details you will see below.

Regarding the comments of the Co-Editor-in Chief:

First, I am surprised by the lack of important data in the text as outlined comprehensively by Reviewer 1 .

Answer: As noted by the reviewer, the tables describe the majority of the results. The manuscript is long and we choose to avoid repetition.

Second, I suggest that you look at the style of presentation of data in other articles published in SURGERY, because there are far too many individual paragraphs. Please either get some help with the organization of the abstract, introduction, and discussion from an outside scientific editing service or group all parts into paragraphs that contain data on the same topic. Third, I would suggest that your co-authors become much more involved in the presentation of the data, which is not well-organized.

Answer: We modified the manuscript to fit more with the editorial request.

Fourth, I just cannot believe that all 26 authors fulfill ALL the ICGME criteria for authorship. Having conducted a prospective randomized trial with 16 other centers (authors) it took me a full 6 months to get every author to read and make suggestions to the text! Here is my suggestion. You should get the four or five co-authors who really were involved in the analysis, the discussion of the topic, and the wiring of the current paper and include them as co-authors. Then, give the study a name, like "French Study group of Bladder Invasion from Colon Cancer." The other contributors who probably only provided patients, but really didn't participate in the actual data collection, analysis of the data, planning on how to organize the paper, and really were not involved in writing of the paper could then be listed in a footnote. I will ask you--did everyone who is listed as an author really read the paper and make suggestions? I am not saying that they may not have received a copy, but, honestly, how many really read it, made substantive suggestions for improvement, and thereby really met ALL the ICGME criteria for authorship? By listing contributors as members of a study group, those other "authors' who really did not participate much can claim authorship if they so desire, but you do not need to include their names as actual authors and thereby have to claim (inappropriately) that they did fulfill all the criteria of the ICGME. Do you understand my approach? You can tell all the other "co-authors" that I demanded this. Those who really did not participate will understand. 
I fully understand your point of view.

As stated, all the authors listed in the article contributed patients, reviewed the manuscript and gave constructive criticism on the manuscript. We made the majority of the corrections and signed off on it during a national meeting where almost all co-authors were in attendance. If you can put some of them as collaborators so they can have their work recognized with an indexed publication on Pubmed it would be fine for us.

If possible, the list of authors would be:

- Cindy Vuillermet, Hélène Meillat, Gilles Manceau, Ben Creavin, Clarisse Eveno, Stéphane Benoist, Yann Parc, Jérémie H. Lefevre; on behalf of the FRENCH research group.

The list of collaborators of the FRENCH research group would be:

- Sara Arfa ${ }^{6}$, Paul-Noël Dumont ${ }^{7}$, Hortense Boullenois ${ }^{8}$, David Fuks ${ }^{9}$, Mehdi Ouaissi ${ }^{10}$, Leonor Benhaim $^{11}$, Marie Selvy ${ }^{12}$, Jean-Jacques Tuech ${ }^{13}$, Zaher Lakkis ${ }^{14}$, Renato Lupinacci ${ }^{15}$, Antoine Epin ${ }^{16}$, Sophie Deguelte ${ }^{17}$, Guillaume Passot ${ }^{18}$, Bertrand Trilling ${ }^{19}$, Cécile Jarlot-Gas ${ }^{20}$, Muriel Mathonnet ${ }^{21}$, David Moszkowicz ${ }^{22}$, Leila M'Harzi ${ }^{23}$, Laura Beyer Berjot ${ }^{24}$.

\section{Concerning the Reviewers' Comments:}

Reviewer \#1: Thank you for allowing us to review your manuscript. This is an important topic, and is generally under-represented in the current literature. Comments:

- The manuscript needs minor orthographic revision.

Answer: The manuscript has been completely reread by a native English speaker (BC).

\section{- Introduction is brief and helpful.}

Answer: Thank you for this nice comment.

- Preop details: please discuss if cases were discussed at multidisciplinary conferences, when is neoadjuvant therapy indicated in France? Is local imaging such as MR used in France? Is has been proven to be helpful to determine the extent of cystectomy in selective cases.

\section{Answer:}

- We do not know if cases were discussed preoperatively in each center in a multidisciplinary conference, as this information was not sought from each center. The cases were likely discussed in a post-operative MDT where decisions on adjuvant therapy would have been made.

- Regarding the indication for neo adjuvant treatment for colonic cancer, the French guidelines “TNCD" (Ref $\left.n^{\circ} 24\right)$ recommend surgery first for all non metastatic tumors, unless there is a doubt on the resectability, in which case neo adjuvant chemotherapy would be discussed. There was indeed a lack of information on this subject, so we added it into the manuscript. 
- MRI is not used routinely in France for preoperative assessment of colonic tumors. Hence it was not utilized in our study. We add some references on this subject, using comparisons with other pelvic tumors, including prostate, rectal or cervical cancers.

- Please provide details of neoadjuvant therapies, including type and duration of chemotherapy, as well as XRT dose. Would also discuss time interval in-between neoadjuvant therapy and surgery.

Answer: We added this information to the text.

- Where any of the conversions started as a diagnostic laparoscopy to rule out carcinomatosis? If so would change this but if indeed a $65 \%$ conversion rate, this is an important point of your study.

Answer: There was no diagnostic laparoscopy for carcinomatosis in this study, as metastatic disease at diagnosis was an exclusion criteria. A $65 \%$ conversion rate does not seem remarkable to us, as only a few surgical teams perform laparoscopic bladder resections (partial, or total).

- How many patients had prophylactic ureteral stent placement?

Answer: We do not have the information about pre-operative ureteral stent placement.

- Change ileal pouch to ileal diversion.

Answer: Done

- Please list organs (including abdominal wall) and extent of resection for patients undergoing multivisceral resection.

Answer: For multivisceral resection, we added the list in Table 2 to the text. We do not have information about the extent of multivisceral resection.

- Did any patients have carcinomatosis? If there were isolated small bowel mets, I would consider this as such and group there prognosis differently.

Answer: No patient had carcinomatosis as it was an exclusion criteria in the study.

- Why was only $86 \%$ resected en bloc? This defies the principles of oncologic resection. This should be looked at as a risk factor for $\mathrm{R} 1$ resection and poor oncologic outcomes.

Answer: As the R1 resection variable encompasses this data, we did not include an en-bloc resection in the univariate analysis.

- Please round up percentages. Reads much better.

Answer: We modified the manuscript.

- Please describe Bricker if you are going to label it that way. Many readers will not know what you're talking about. 
Answer: We removed this term to talk only about total cystectomy.

- Did neoadjuvant therapy impact postop complications? Would group all and also have a separate analysis of chemo and XRT patients.

Answer: The morbidity rate was not impacted by neoadjuvant treatment. As the numbers are small, we were reluctant to detail these subgroups.

- Did sending frozen sections impact final pathology results? Discuss in results.

Answer: We added a sentence in the results section

- Did any patients undergo fecal diversion, temporary or permanent? Would also add this.

Answer: Information about temporary stoma formation is in Table 2, we have added this to the text also.

- Histologic variables should also include degree of differentiation, mucinous features, and signet-cell features; and LR or metastatic disease should be analyzed according to tumor biology as this tends to be one of the most important factors.

Answer: Information about histological features such as histologic type and grade of differentiation can be found in Table 3.

- What was the definition of confirmed vs. non confirmed bladder invasion? This is confusing to me.

Answer: Confirmed bladder invasion includes a pathological confirmation of infiltration of the bladder by colonic cancer.

- Please provide details regarding duration of adjuvant chemotherapy. Would also be helpful to provide interval between surgery and start of adjuvant chemotherapy, adverse events, and any interruptions; and how all this impacted oncologic outcomes.

Answer: We have added some details about adjuvant chemotherapy. We do not have any information about the adverse events of adjuvant chemotherapy, as it was not the subject of our study.

- The neoadjuvant effect should be highlighted in the abstract.

Answer: done.

- How do you explain the non significant differences in 3-year bladder LR in R0 and R1 patients? Neoadjuvant therapy? Tumor biology? Adjuvant chemo?

Answer: We were surprised by this important finding and have given some possible explanation in the discussion. 
- Explain "bladder boundary". Very confusing.

Answer: We removed this term from the article.

- How many surgeons were involved in the treatment of these patients? Please add.

Answer: We do not have the exact number of surgeons involved in this study. It was multicentric including 23 centers.

- Discussion: would emphasize differences in function and QoL a bit more between partial and total cystectomy patients, and potentially reference a paper with this. Comment on the use of MR to predict bladder invasion.

Answer: We added to the discussion regarding quality of life after radical cystectomy. As explained earlier, we added some references, mainly using comparisons with other pelvic tumors, including prostate, rectal or cervical cancers.

- Additional limitations: multiple different centers and surgeons treating these patients, different work-up algorithms, as well as different neoadjuvant and adjuvant strategies.

Answer: We agree with this point. We added the multicentric nature of the study in the limitation section.

- Tables and Figures are helpful and partially address some of the questions/comments above.

Answer: We thank the reviewer for this gentle remark.

Reviewer \#2: The authors present a retrospective multicenter observational study of patients with colon cancer invading the bladder. There 117 patients included in the analysis. $92 \%$ were treated with partial cystectomy, $26 \%$ received neoadjuvant therapy and interestingly only $47 \%$ were confirmed to have T4b tumors with direct invasion into the bladder. 3 year DFS was low at 59\%. Local recurrence was higher after R1 vs R0 resection and was the only predictor of local recurrence. This is interesting data but there are several issues that need to be addressed.

Answer: We thank the reviewer for this nice comment on our work.

1) Methods -- Did all patients meet inclusion criteria prior to their resection? Specifically, differentiating between a planned partial cystectomy and an intra-operative decision can greatly impact the extent of resection so understanding this is important to understanding a $13 \% \mathrm{R} 1$ resection rate. Also, specify if patients were included based on imaging, path or both. How the study group was defined needs to be more clearly defined.

Answer: We gave specific and clear inclusion and exclusion criteria to all centers. If patients did not fit with all the criteria, they were excluded from the study. In fact, 253 patients were screened in the 23 centers, and 117 patients were included in the end. The primary inclusion 
criteria was a bladder resection for colorectal cancer. It explains why $37 \%$ of patients had no work-up before surgery and may, at least in part, explain also the Rl rate.

2) Results -- $63 \%$ of patients had suspected bladder involvement so what about the other $37 \%$ ? What did the work up for those suspected involvement -- imaging...?

Answer: Only 74 patients (63\%) were suspected of having a clinical invasion of the bladder in the pre-operative setting, so for the rest of the cohort (37\%), it was an intraoperative diagnosis of a T4 tumor adherent to the bladder.

3) Results -- Only $47 \%$ of patients truly had T4 disease so shouldn't the denominator be 55 patients? The title of paper should reflect the total patient population -- Suspected bladder invasion. An analysis of all patients with subset analysis of those with T4 (a and b) and T3 would be most helpful. Inclusion of T3 tumors must have impacted your LR rate for $\mathrm{RO}$ resections.

Answer: We agree with this important observation. However, all patients had a clinical bladder invasion justifying the resection. We modified the title to highlight this point.

Therefore, we do not agree to using 55 patients as a denominator, because it reflects only the final classification after surgery and definitive histology, and not the daily clinical practice when you have to deal with this kind of clinical situation. Our aim with this study was to help surgeons propose the best strategy for a patient with a pre-operative suspicion of bladder invasion, or an intra-operative finding, and how to deal with the local recurrence risk. Hence the study is presented this way.

4) Results -- It would be helpful to present your data in a manner that supports a partial cystectomy in the face of poor pre-operative predictability bladder involvement.

Answer: We agree with this important observation and added this point in the conclusion.

5) Results -- For bladder recurrence, how did T stage impact recurrence rates?

Answer: We cannot say that the T stage impacted bladder recurrence, as bladder recurrence was found even without histologically confirmed invasion at index surgery (4 patients, 36\%).

6) Discussion -- The discussion is too long and needs to focus on the findings of this study. The references should then be used to support and enhance the specific findings of this study.

Answer: We modified the discussion as requested.

7) Discussion -- The major limitation of this study is the study group is not well defined. Based on the title, the reader is expecting this to be exclusively $\mathrm{T} 4$ tumors but only $47 \%$ were in fact $\mathbf{T} 4$. So context of the study becomes confusing. Also, as mentioned above, differentiate between pre- and intra-operative identification of patients. The major take home message of the study is be prepared to resect bladder with the tumor if suspected involvement and neoadjuvant therapy is good. The issues above cloud that message. 
Answer: To cope with these remarks, the title has been modified and we clarified the aim of the study. 


\section{ASSISTANCE $\succsim$ HÔPITAUX \\ PUBLIQUE DE PARIS}

To the Editor-in-Chief

Dear Sir,

Please find attached a manuscript entitled "Bladder invasion in advanced colonic cancer: outcomes and prognosis from a multicentric study of 117 patients. A multicentric series of the FRENCH research group.' which is submitted to Surgery as an original article.

We present a multicentric study of 117 advanced colonic cancers with a bladder invasion from 23 centres.

To our knowledge, there is a lack of studies examining the management of bladder involvement in colorectal cancer, mainly due to the relatively limited frequency of the problem in most institutions.

We believe that this work will have a clinical impact for the surgeons. Indeed, Clinical bladder invasion is at risk for local recurrence even without pathological bladder invasion. Only optimal surgery with R0 margins was the only protecting factor for local recurrence. In all cases a strong surveillance is needed, even without pathological bladder invasion.

By submitting the manuscript, the authors understand that the material presented in this paper has not been published before, has not been submitted for publication to another scientific journal, and will not be sent to another journal until a decision is made concerning publication. I attest that this work has been approved by all co-authors. The authors also understand that should the submitted material be accepted for publication in the journal, they will automatically transfer the copyright to the publisher. Authors have no conflicts of interests and no funding source to declare.

Thank you for considering this manuscript for publication in Surgery.

Yours sincerely,

The authors 
Advanced colonic cancer with clinically suspected bladder invasion: outcomes and

prognosis from a multicentric study of 117 patients from the FRENCH research group.

Cindy Vuillermet ${ }^{1}$, Hélène Meillat ${ }^{2}$, Gilles Manceau ${ }^{3}$, Ben Creavin ${ }^{4}$, Clarisse Eveno ${ }^{5}$,

Stéphane Benoist ${ }^{6}$, Yann Parc ${ }^{1}$, Jérémie H. Lefevre ${ }^{1}$; on behalf of the FRENCH research group.

${ }^{1}$ Sorbonne Université, Department of Digestive Surgery, AP-HP, Hôpital Saint Antoine, F75012, Paris, France.

${ }^{2}$ Department of Surgical Oncology, Institut Paoli-Calmettes, Marseille, France

${ }^{3}$ Department of Digestive Surgery, Pitié Salpêtrière Hospital, AP-HP, Sorbonne University, Paris, France

${ }^{4}$ Department of Surgery, St Vincent's University Hospital, Elm Park, Dublin 4, Ireland

${ }^{5}$ Department of Digestive and Oncological Surgery, University Hospital C. Huriez, Lille, France

${ }^{6}$ Department of Digestive Surgery, Bicêtre Hospital, University Paris Sud XI, 7, Le KremlinBicêtre, France

\section{List of collaborators of the FRENCH research group:}

- Sara Arfa, Department of Digestive Surgery, University Hospital of Dijon, Dijon, France

- Paul-Noël Dumont, Department of General Surgery and Liver Transplantation, Hôpital de la Croix-Rousse, Hospices Civils de Lyon, University Lyon 1, Lyon, France

- Hortense Boullenois, Department of Digestive Surgery, Bicêtre Hospital, University Paris Sud XI, 7, Le Kremlin-Bicêtre, France.

- David Fuks, Department of GI Surgery, Institut Mutualiste Montsouris, Paris, France

- Mehdi Ouaissi, Department of Digestive Surgery, Tours, France

- Leonor Benhaim, Department of Visceral and Oncological Surgery, Gustave Roussy, Villejuif, France

- Marie Selvy, Digestive Surgery and Oncological Department, Hospital Estaing, Clermont-Ferrand, France 
- Jean-Jacques Tuech, Department of Digestive Surgery, Rouen University Hospital, Rouen, France

- Zaher Lakkis, Department of Digestive Surgery, Besançon University Hospital, Besançon, France

- Renato Lupinacci, Department of Digestive, Visceral and Endocrine Surgery, Groupe Hospitalier Diaconesses - Croix Saint-Simon, France

- Antoine Epin, Department of Digestive and Oncologic Surgery, CHU Nord Saint-Etienne, Saint-Priest en Jarez

- Sophie Deguelte, Department of General and Digestive Surgery, Robert Debré Hospital, Centre Hospitalier Universitaire de Reims, University of Reims Champagne-Ardenne, Reims, France

- Guillaume Passot, Department of Digestive Surgery, Centre Hospitalier Lyon Sud, University Claude Bernard Lyon 1, Lyon, France

- Bertrand Trilling, Department of Surgery, Colorectal Unit, Michallon University Hospital, University Grenoble Alps, Grenoble, France

- Cécile Jarlot-Gas, Department of Visceral Surgery, Toulouse-Rangueil University Hospital, Toulouse, France

- Muriel Mathonnet, Department of Digestive, General and Endocrine Surgery, CHU de Limoges - Dupuytren Hospital, Limoges, France

- David Moszkowicz, Department of Digestive, Oncologic and Metabolic Surgery, Ambroise-Paré Hospital, Boulogne-Billancourt, AP-HP, University of VersaillesSaint-Quentin-en-Yvelines, France

- Leila M'Harzi, Department of Digestive, Oncologic and Bariatric Surgery, AP-HP, Hôpital Européen Georges Pompidou and University Paris Descartes, Paris

- Laura Beyer Berjot Department of Digestive Surgery, APHM, Hôpital Nord, AixMarseille University, Marseille, France

\section{Correspondance and reprint requests:}

Pr Jérémie H. Lefèvre, Department of Digestive Surgery, Hôpital Saint-Antoine, Assistance Publique Hôpitaux de Paris, Université Pierre et Marie Curie, Paris VI, 184 rue du Faubourg Saint-Antoine, 75012, Paris, France

Tel: 00331492825 47, Fax: 0033149282548

e-mail: jeremie.lefevre@aphp.fr

ORCID: https://orcid.org/0000-0001-7601-7464

\section{Original article}

Running head: Bladder invasion in advanced colon cancer. 
Disclosure: No authors reported conflict of interest.

Keywords: Locally advanced colon cancer; bladder invasion; local recurrence; urinary tract involvement; enbloc resection.

Word count: 2833

Abstract count: 249 
Objective: Report outcomes and identify risk factor for local recurrence (LR) in colon cancer with clinically suspected bladder invasion.

Background: Bladder invasion by colon cancer is rare, however, its management is still controversial

Methods: A retrospective study was conducted in 23 centers. All patients who underwent colon surgery with bladder resection (2010-2017) were included. Metastatic and recurrent colon cancers were excluded.

Results: 117 patients (men=73) were included. Partial cystectomy occurred in 108 patients (92.3\%), with a total cystectomy occurring in 9 patients (7.7\%). Neoadjuvant treatment was given to 31 patients (26.5\%). Major morbidity was $20.5 \%$. R0 resection rates were $87.2 \%$. Histologically confirmed bladder invasion was seen in $47 \% .34$ patients were $\mathrm{pN}+$, while 60 patients $(51.3 \%)$ received adjuvant chemotherapy. Mean follow-up was 33.8 months. 3-year OS and DFS were $82.9 \%$ and $59.5 \%$. LR and distant recurrence rates were $14.5 \%$ and $18.8 \%$, respectively. $64.7 \%$ of LR were located in the bladder (11 patients). 4 patients had a bladder recurrence (BR) despite not having histologically confirmed bladder invasion at index surgery. The BR rate after bladder invasion was $12.7 \%$ (7/55), while the BR rate without primary bladder invasion was $6.5 \%(4 / 62)(\mathrm{p}=0.343)$. The $\mathrm{R} 1$ resection rate after partial cystectomy was $57 \%$ (4/7), while the R0 resection rate was $6.8 \%$. Neoadjuvant treatment, type of cystectomy and adjuvant treatment did not influence LR ( $\mathrm{p}=0.659, \mathrm{p}=0.445, \mathrm{p}=0.941)$. R1 bladder resections increased LR ( $62.5 \%$ vs. $10.2 \%$, p $<0.0001)$.

Conclusions: Clinically suspected bladder invasion increases LR even in the absence of histologically confirmed bladder invasion. Only optimal surgery with R0 margins reduces LR. Strong surveillance is needed, even without pathological bladder invasion. 


\section{INTRODUCTION}

Local invasion into adjacent organs by primary colorectal cancer occurs in 5-20\% of cases, ${ }^{1-4}$ with urinary tract involvement accounting for $10-30 \%$ of this. ${ }^{5-9}$ En-bloc resection of all involved organs to leave no residual cancer is recognized as the gold standard treatment for locally advanced colorectal cancer. ${ }^{10,11}$ Improved survival is associated with an R0 resection in these cases, however, achieving this is challenging. ${ }^{12}$ Furthermore, bladder invasion can be encountered intra-operatively without patients undergoing neoadjuvant therapy or appropriate staging which can further impact on resection margins and patient outcomes. Total cystectomy with urinary diversion is the oncologic resection of choice for bladder invasion, although this is associated with significant morbidity and quality of life issues. ${ }^{13-15}$ Therefore, the choice of a partial or total cystectomy becomes an important consideration when balancing both oncological outcomes and quality of life.

Management of bladder invasion is still controversial. Local recurrence is not uncommon (roughly $10-30 \%$ ), with no definitive contributing factors being identified. ${ }^{6,8,9,14,16-19}$ Seeding of tumor cells into the bladder may go unnoticed for a long time prior to resection due to the bladder being a hollow viscus. Furthermore, the rate of bladder recurrence is rarely detailed in previous publications. To our knowledge, there is a lack of studies examining the management of bladder involvement in colorectal cancer, mainly due to the relatively limited frequency of the problem in most institutions. Table 1 summarizes the published data to date on this topic.

The aim of this study was to report surgical and oncological outcomes and identify potential risk factors of local recurrence after bladder invasion in primary advanced colon cancer.

\section{METHODS}




\section{Patients}

All patients who underwent colonic resection for a primary advanced adenocarcinoma with bladder resection for clinically suspected bladder invasion between 2010 and 2017 were retrospectively included from 23 digestive oncologic surgery departments in France, belonging to the FRENCH Group. Exclusion criteria included patients $<18$ years old, resections for local recurrences, mid or low rectal cancer, synchronous metastatic disease and emergency surgery. Each center sent data through an anonymized database or secure online survey. Information regarding demographic data, clinical symptoms leading to diagnosis, type of surgery, neoadjuvant and adjuvant oncological treatments, postoperative outcomes and follow-up were recorded.

\section{Management}

Pathological staging of the tumor was in accordance with the AJCC Cancer Staging $8^{\text {th }}$ edition. ${ }^{20}$ Modified Dworak Tumor Regression Grade system was used to analyze tumor response to neoadjuvant therapy. Clavien Dindo's classification was used to grade morbidity. ${ }^{21}$ The RECIST 1.1 classification was used as imaging criteria for assessing tumor response. ${ }^{22}$ Data regarding neoadjuvant treatment was retrieved retrospectively. Indications for neoadjuvant treatment were discussed in each center individually, in line with French guidelines. Neoadjuvant chemotherapy is recommended in non-metastatic disease where tumor resectability is questioned. ${ }^{23}$ Data regarding adjuvant treatment was retrieved retrospectively. Adjuvant chemotherapy regimens were chosen at individual centers in accordance with French and European guidelines. ${ }^{24}$ Currently, adjuvant chemotherapy is recommended for stage III or stage II disease with risks factors. Follow-up was conducted according to each centers preference. French guidelines recommend physical examination and CT scan every 3 months for the first three years, then 6 monthly thereafter for 2 years. ${ }^{23}$ Local recurrence was defined 
as a recurrence near the primary site of resection, with a bladder recurrence defined as a recurrence inside or on the bladder after partial cystectomy. All data was anonymized. The study was declared with the CNIL (no: 2212340).

\section{Statistical analysis}

Qualitative variables were described as number (\%) and were compared between groups using Pearson $\mathrm{Chi}^{2}$ test or Fisher's exact test. Quantitative variables were described as mean $\pm \mathrm{SD}$. Positive and negative predictive values were calculated to assess the accuracy of the preoperative examinations. Survival curves were plotted using the Kaplan-Meier method. Logrank test was used to compare survival curves. Potential prognostic factors were evaluated using Cox proportional hazard regression models. Survival time was the interval between the intervention date and a new event or last follow-up. Patients who did not experience any event and were still alive at the end of follow-up were right censored at this time. For each outcome, factors achieving a p value $<0.20$ in the univariate analysis were included in the multivariate model. Hazard ratio were presented with $95 \%$ confidence intervals. All statistical tests were two-sided and performed using SAS software version 9.3; SAS Institute Inc., Cary, NC, USA.

\section{RESULTS}

\section{Patients and preoperative management}

From January 2010 to December 2017, 117 patients across 23 French centers who underwent colectomy with bladder resection for primary advanced colon cancer were included. Patient characteristics are detailed in Table 2.73 patients were male (62\%). Mean age was 70.3 years (+/13.4). Bladder invasion (clinically T4) was suspected on preoperative investigations and/or with clinical symptoms in 74 (63\%) patients. 23 patients had a preoperative cystoscopy (20\%), with a macroscopic bladder invasion found in 15 patients. Histological confirmation of bladder 
invasion was confirmed in 5 of these patients. Intra-operative bladder invasion was found in 43 patients (37\%) who were either asymptomatic or not suspected of having invasion on preoperative investigations. 31 patients had neoadjuvant therapy (26\%), with the majority having chemotherapy alone ( $\mathrm{n}=22 ; 71 \%)$. Chemotherapy consisted mainly of folinic acid-fluorouracil and oxaliplatin (Table 2). After neoadjuvant therapy, 20 (64\%) patients were RECIST 2 with partial response. No patient had a complete response. The median time between the end of neoadjuvant treatment and surgery was 5 weeks (IQR 4.8-6.7).

\section{Oncological resection and postoperative course}

$34(29 \%)$ patients underwent laparoscopic resection, of which, 22 (65\%) were converted to open (Table 2). Nine patients (8\%) had a total cystectomy with definitive urinary ileal conduit with 108 patients having a partial cystectomy. 54 patients (46\%) had an associated procedure with another organ resected, the most frequent being a small bowel resection (22 patients, $41 \%)$. Intra-operative frozen section was utilized in 26 patients (22\%), with 6 (23\%) positive results. En-bloc resection was performed in 101 patients (86\%). Overall morbidity was 55\%, with severe morbidity encountered in 18\% (Table 3). There was 3 postoperative deaths (3\%), all after partial cystectomy (one due to a pulmonary embolism and two for unknown causes). 10 patients (10\%) had an anastomotic leak, with 25 patients (21\%) having urinary related morbidity. After partial cystectomy, overall and severe morbidity was 55\% and $18 \%$ respectively. Bladder leak occurred in 11 patients (10\%) after partial cystectomy. Following total cystectomy and urinary ileal conduit, overall and severe morbidity was $55 \%$ and $22 \%$ respectively, with an ileal-diversion related morbidity of $44 \%$. There was no significant difference in overall $(\mathrm{p}=1)$ and severe morbidity $(\mathrm{p}=0.663)$ after partial or total cystectomy. 


\section{Pathological outcomes and adjuvant treatment}

Pathological invasion of the bladder was confirmed in 55 patients $(47 \%)$. The negative predictive value of the cT stage for the diagnosis of histologically proven bladder invasion was $70 \%$, with a positive predictive value of $53 \%$. An R0 resection was achieved in $87 \%$ of the cohort. R1 resections differed significantly between patients with a confirmed bladder invasion $(13 / 54)$ and those without confirmation $(2 / 62)(\mathrm{p}<0.0001)$ (Table 3$) .60$ patients $(51 \%)$ received adjuvant chemotherapy, with the majority undergoing a FOLFOX regimen $(n=49,82 \%)$. Median number of administered cycles was 8 (4-12), with the mean interval between surgery and initiation of adjuvant chemotherapy of $8.5 \pm 4$ weeks. Factors associated with adjuvant chemotherapy administration included lymph node invasion $(\mathrm{N}+$ stage $)$ in 24 patients, $\mathrm{T} 4 \mathrm{~b}$ stage without lymph node invasion in 29 patients and adverse pathological features in 7 patients (T4a, low differentiation grade, T3).

\section{Long term follow-up and recurrences}

Mean follow up was 33.8 \pm 24.3 months. Mortality rate was $15 \%$ (18 patients). 3-year OS and DFS were $83 \%$ and $59 \%$, respectively. 3-year local and distance recurrence rates were $17 \%$ and $24 \%$, respectively (figure $1 \mathrm{~A} \& 1 \mathrm{~B}$ ). Median time to recurrence was 10.5 months (IQR= 6.1-16.6). 17 patients (53\%) had a LR (14\% after partial cystectomy and $22 \%$ after total cystectomy). Among the 74 patients with cT4 stage, 27 patients received neoadjuvant treatment. LR rate was not influenced by either neoadjuvant treatment ( $15 \%$ vs. $21 \%, p=0.762)$ or adjuvant treatment $(15 \%$ vs. $14 \%, \mathrm{p}=1)$. Eleven $(10 \%)$ patients had recurrence inside the bladder following partial cystectomy after a median interval of 11.9 months (IQR=7.6-14.1). 4 patients $(36 \%)$ developed a bladder recurrence who did not have histologically confirmed invasion at index surgery. Bladder recurrence rates after partial cystectomy with invasion of 
the bladder margin (R1) was 57\% (4/7), while recurrence rates were $7 \%$ for R0 resections. The 3-year bladder recurrence rate was similar between patients with an invaded bladder and R0 resection margin to those without bladder invasion (9\% vs. 8\%) (Figure 2). In univariate analysis, factors significantly associated with local recurrences were R1 resections $(\mathrm{p}<0.001)$ and invasion of the bladder margin $(\mathrm{p}<0.01)$. Performing a partial instead of a total cystectomy was not associated with a higher local recurrence. Furthermore, bladder invasion on histological analysis was not associated with a higher LR risk (Table 4). In multivariate analysis, the only independent factor associated with a LR was an R1 bladder resection (62.5\% vs. $10.2 \%, \mathrm{p}<0.0001)$.

\section{DISCUSSION}

This multicentric retrospective study reported both surgical and oncological outcomes of 117 patients with a clinically suspected bladder invasion from a locally advanced colon cancer. The study showed that histologically proven bladder invasion was found in less than half of patients undergoing a partial or total cystectomy with a colonic resection. Furthermore, after partial cystectomy, bladder local recurrence rates were $9 \%$ even without confirmed bladder invasion on histological exam.

117 patients were included from 23 FRENCH research group centers over 8 years, from 2010 to 2017, in order to collect recent data on surgical management of these patients. This is, to our knowledge, the largest series to date with a short and recent time period examining this topic. Patients in the study were mostly men (62\%), with a mean age at diagnosis of 70.3 years. These results are in concordance with previous studies. ${ }^{2,12,14-16,18,25-28}$ As the inclusion criteria for the present study was a clinically suspected invasion of the bladder, the rate of pathological bladder invasion at the time of the histological analysis was $47 \%$. This result is in concordance 
with most studies where less than half of patients have true pathological invasion. This is well demonstrated in Eveno et al. study on cT4 colorectal cancers where a pathological invasion rate of $64 \%$ for all organs was encountered. ${ }^{7}$ This observation may explain in part the R1 resection rate observed in the study. Intraoperative assessment of bladder adherence is often inaccurate and should not be considered relevant for choosing the type of bladder resection. In fact, even without pathological bladder invasion, a clinical T4 tumor should not be considered as a simple $\mathrm{T} 3$ in adjuvant treatment decision making and follow-up due to a high risk of local recurrence. Gao et al. found that both groups, with and without pathological bladder invasion, have similar survival outcomes. ${ }^{14}$

The 3 years overall survival was $82.9 \%$ which was higher than the survival rates found in the previous literature. This can be explained by the exclusion of metastatic disease at the time of diagnosis and emergency surgery which is a known adverse prognostic factor. The LR rate of $14 \%$, with $65 \%$ of these located in the bladder, in the present study is in keeping with previous reports (Table 1). Surprisingly, the LR rate inside the bladder after pathological bladder invasion $(13 \%)$ was higher, but nonetheless not significantly different $(\mathrm{p}=0.342)$ without pathological bladder invasion (7\%). Moreover, after exclusion of R1 resection, the rate was similar between the groups. Yoshida et al. recently found that bladder recurrence is related to a transfixing bladder invasion at the time of surgery. ${ }^{19}$ This was not the case in the present study, possibly due to the lack of data regarding the depth of bladder invasion. However, several patients in the present study who did not have bladder invasion at index surgery had a recurrence within the bladder several years later. An R1 resection is a known risk factor for LR, something that was encountered again in the present study. ${ }^{4,12,18}$ Bladder recurrence rates following a partial cystectomy with R1 resection was 57\% compared with 7\% in the R0 group. Completion total cystectomy may be warranted in these cases due to the poor prognostic outcomes. Close follow up of all patients is also extremely important even if there is no 
consensus on the frequency or modalities required for follow up, however, an annual cystoscopy may be warranted after partial cystectomy. Mechanisms leading to bladder recurrence without proof of bladder invasion by tumor cells at the time of histological analysis is still unknown. A physiopathological hypothesis of this may be that some colonic tumor cells are circulating within the bladder cavity in the urine and would not be seen on histological examination. This circulation of tumor cells inside the bladder is probably helped by inflammation due to the bulky colonic tumoral mass nearby, although, the presence of a colovesical fistula may be present in some instances.

An overall morbidity of $55 \%$ was encountered in this study. Morbidity rates vary across the studies, with rates between $10-70 \%$ being reported. ${ }^{2,3,7,14-16,18,19,25,27-29}$ Severe morbidity was slightly lower after partial cystectomy compared to total cystectomy with urinary ileal conduit (18\% versus $22 \%$ ). The rate of bladder leak after partial cystectomy was $10 \%$, whereas the rate of morbidity related to ileal conduit was $44 \%$. It is known that urinary diversion, such as ileal conduit or replacement enterocystoplasty, carry additional morbidity. ${ }^{14,25}$ Gao et al. found a significantly higher morbidity after total cystectomy than partial cystectomy. ${ }^{14} \mathrm{Li}$ et al. found a higher complication rate after reconstruction (81\%) than simple suture $(45 \%) .{ }^{15}$ These results would favor a simple suture partial cystectomy over an enterocystoplasty or ileal conduit if possible. Furthermore, it has been demonstrated that radical cystectomy with ileal conduit can have a major impact on health-related quality of life, especially in the early stages. ${ }^{30-32}$ Voiding dysfunction can occur after simple suture due to impaired bladder volume, although this is not frequent. ${ }^{28}$ Long-term functional results were not evaluated in this study.

Neoadjuvant treatment did not influence LR in univariate analysis $(\mathrm{p}=0.659)$ in the present study. Dehal et al. showed that neoadjuvant chemotherapy improves 3-year overall survival in a subgroup of T4b cancers, although this was not seen in T3 or T4a tumors. ${ }^{33}$ This may explain the discrepancy seen in the present study as only $55 \%$ of pT4a tumors were encountered. A 
prospective study published by Qiu et al. reported an R0 resection rate of $95.2 \%$ after neoadjuvant chemoradiotherapy in unresectable locally advanced colon cancers, with a pathological complete response rate of $38 \% .{ }^{34} \mathrm{~A}$ phase III prospective randomized clinical trial is currently underway to validate the role of neoadjuvant therapy in locally advanced primary colon cancer. ${ }^{35}$ However, neoadjuvant treatment needs a preoperative diagnosis of bladder invasion, however, as observed in the present study, pre-operative investigations are not accurate at identifying this. The positive and negative predictive values of CT imaging was $53 \%$ and $70 \%$. Luo et al. found that a positive preoperative CT scan is a significant predictor for pathological bladder invasion, as well as a colovesical fistula. ${ }^{27}$ In a retrospective study published by Woranisarakul et al., haematuria, visible tumor on cystoscopy and CT findings were predictive factors for invasion, with specificity around $70 \%-90 \%$, although a low sensitivity of $50 \% .{ }^{26}$ Regarding the usefulness of a preoperative pelvic MRI, this was not evaluated in this study as it is not used routinely in France for colon cancer. Indeed, in prostate and cervical cancer, MRI has proven its efficacy in confirming bladder invasion ${ }^{3637}$. Further studies on the precise preoperative investigations are required to provide a consensus on this issue.

This study is limited by its retrospective nature. As this is a rare occurrence the sample size was limited, however, it is strengthened by combining multiple centers. Follow up was short, although the authors feel the majority of recurrences were captured within the time frame. Another limitation, resulting from the multicentric and retrospective nature of the study, is the variety of procedures, strategies and habits in each center, which add to the heterogeneity of the study.

Partial cystectomy seems to be the procedure of choice in cases of bladder invasion by a colon cancer if safe and clear margins can be obtained. Strong surveillance is needed, even without pathological bladder invasion as local recurrence may occur. Questions such as neoadjuvant 
treatment, details regarding surveillance and preoperative investigations still need to be explored.

\section{REFERENCES}

1. Eldar S, Kemeny MM, Terz JJ. Extended resections for carcinoma of the colon and rectum. Surg Gynecol Obstet. 1985;161:319-22.

2. Carne PW, Frye JN, Kennedy-Smith A, Keating J, Merrie A, Dennett E, et al. Local invasion of the bladder with colorectal cancers: surgical management and patterns of local recurrence. Dis Colon Rectum. 2004;47:44-7.

3. Kobayashi T, Kamoto T, Sugino Y, Takeuchi H, Habuchi T, Ogawa O. High incidence of urinary bladder involvement in carcinomas of the sigmoid and rectum: a retrospective review of 580 patients with colorectal carcinoma. J Surg Oncol. 2003;84:209-14.

4. Delacroix SE, Jr., Winters JC. Bladder Reconstruction and Diversion during Colorectal Surgery. Clin Colon Rectal Surg. 2010;23:113-8.

5. Bretagnol F, Dedieu A, Zappa M, Guedj N, Ferron M, Panis Y. T4 colorectal cancer: is laparoscopic resection contraindicated? Colorectal Dis. 2011;13:138-43.

6. Croner RS, Merkel S, Papadopoulos T, Schellerer V, Hohenberger W, Goehl J. Multivisceral resection for colon carcinoma. Dis Colon Rectum. 2009;52:1381-6.

7. Eveno C, Lefevre JH, Svrcek M, Bennis M, Chafai N, Tiret E, et al. Oncologic results after multivisceral resection of clinical T4 tumors. Surgery. 2014;156:669-75.

8. Lehnert T, Methner M, Pollok A, Schaible A, Hinz U, Herfarth C. Multivisceral resection for locally advanced primary colon and rectal cancer: an analysis of prognostic factors in 201 patients. Ann Surg. 2002;235:217-25. 
9. Campos FG, Calijuri-Hamra MC, Imperiale AR, Kiss DR, Nahas SC, Cecconello I. Locally advanced colorectal cancer: results of surgical treatment and prognostic factors. Arq Gastroenterol. 2011;48:270-5.

10. Sugarbaker ED. Coincident removal of additional structures in resections for carcinoma of the colon and rectum. Ann Surg. 1946;123:1036-46.

11. Hunter JA, Ryan JA, Jr., Schultz P. En bloc resection of colon cancer adherent to other organs. Am J Surg. 1987;154:67-71.

12. Weinstein RP, Grob BM, Pachter EM, Soloway S, Fair WR. Partial cystectomy during radical surgery for nonurological malignancy. J Urol. 2001;166:79-81.

13. Cavdar I, Temiz Z, Ozbas A, Can G, Tarhan F, Findik UY, et al. Sleep and quality of life in people with ileal conduit. Scand J Urol. 2016;50:472-6.

14. Gao F, Cao YF, Chen LS, Zhang S, Tang ZJ, Liang JL. Outcome of surgical management of the bladder in advanced colorectal cancer. Int J Colorectal Dis. 2007;22:21-4.

15. Li JC, Chong CC, Ng SS, Yiu RY, Lee JF, Leung KL. En bloc urinary bladder resection for locally advanced colorectal cancer: a 17-year experience. Int J Colorectal Dis. $2011 ; 26: 1169-76$.

16. Hartwig MF, Bulut O, Niebuhr M, Thind P, Steven K, Bulow S. Local involvement of the lower urinary tract in primary colorectal cancer - outcome after en-bloc resection. Pol Przegl Chir. 2016;88:99-105.

17. Hotta T, Takifuji K, Yokoyama S, Matsuda K, Higashiguchi T, Tominaga T, et al. Survival in colorectal cancer patients with urinary tract invasion. Dis Colon Rectum. 2006;49:1399-409. 
18. Winter DC, Walsh R, Lee G, Kiely D, O'Riordain MG, O'Sullivan GC. Local involvement of the urinary bladder in primary colorectal cancer: outcome with enbloc resection. Ann Surg Oncol. 2007;14:69-73.

19. Yoshida T, Shida D, Taniguchi H, Tsukamoto S, Kanemitsu Y. Long-Term Outcomes Following Partial Versus Complete Cystectomy in Advanced Colorectal Cancer with Regarding to the Extent of Bladder Invasion. Ann Surg Oncol. 2019;26:1569-76.

20. Weiser MR. AJCC 8th Edition: Colorectal Cancer. Ann Surg Oncol. 2018;25:1454-5.

21. Dindo D, Demartines N, Clavien PA. Classification of surgical complications: a new proposal with evaluation in a cohort of 6336 patients and results of a survey. Ann Surg. 2004;240:205-13.

22. Eisenhauer EA, Therasse P, Bogaerts J, Schwartz LH, Sargent D, Ford R, et al. New response evaluation criteria in solid tumours: revised RECIST guideline (version 1.1). Eur J Cancer. 2009;45:228-47.

23. Lecomte T, Andre T, Bibeau F. «Cancer du côlon non métastatique » Thésaurus National de Cancérologie Digestive. . 2019.

24. Labianca R, Nordlinger B, Beretta GD, Mosconi S, Mandala M, Cervantes A, et al. Early colon cancer: ESMO Clinical Practice Guidelines for diagnosis, treatment and follow-up. Ann Oncol. 2013;24 Suppl 6:vi64-72.

25. Fujisawa M, Nakamura T, Ohno M, Miyazaki J, Arakawa S, Haraguchi T, et al. Surgical management of the urinary tract in patients with locally advanced colorectal cancer. Urology. 2002;60:983-7.

26. Fuhrman GM, Talamonti MS, Curley SA. Sphincter-preserving extended resection for locally advanced rectosigmoid carcinoma involving the urinary bladder. J Surg Oncol. 1992;50:77-80. 
27. Luo HL, Tsai KL, Lin SE, Chiang PH. Outcome of urinary bladder recurrence after partial cystectomy for en bloc urinary bladder adherent colorectal cancer resection. Int J Colorectal Dis. 2013;28:631-5.

28. Nerli RB, Ghagane SC, Ram P, Shimikore SS, Vinchurkar K, Hiremath MB. Bladder Invasion in Patients with Advanced Colorectal Carcinoma. Indian J Surg Oncol. 2018;9:547-51.

29. Balbay MD, Slaton JW, Trane N, Skibber J, Dinney CP. Rationale for bladder-sparing surgery in patients with locally advanced colorectal carcinoma. Cancer. $1999 ; 86: 2212-6$.

30. Zietman A, Skinner E. Quality of life after radical treatment for invasive bladder cancer. Semin Radiat Oncol. 2005;15:55-9.

31. Arman T, Mher B, Varujan S, Sergey F, Ashot T. Health-related quality of life in patients undergoing radical cystectomy with modified single stoma cutaneous ureterostomy, bilateral cutaneous ureterostomy and ileal conduit. Int Urol Nephrol. 2020.

32. Normann CO, Opheim R, Andreassen BK, Bernklev T, Haug ES. Health-related quality-of-life after radical cystectomy among Norwegian men and women compared to the general population. Scand J Urol. 2020:1-7.

33. Dehal A, Graff-Baker AN, Vuong B, Fischer T, Klempner SJ, Chang SC, et al. Neoadjuvant Chemotherapy Improves Survival in Patients with Clinical T4b Colon Cancer. J Gastrointest Surg. 2018;22:242-9.

34. Qiu B, Ding PR, Cai L, Xiao WW, Zeng ZF, Chen G, et al. Outcomes of preoperative chemoradiotherapy followed by surgery in patients with unresectable locally advanced sigmoid colon cancer. Chin J Cancer. 2016;35:65. 
35. Foxtrot Collaborative G. Feasibility of preoperative chemotherapy for locally advanced, operable colon cancer: the pilot phase of a randomised controlled trial. Lancet Oncol. 2012;13:1152-60.

36. Ren J, Huan Y, Li F, Wang H, Ge Y, Chang Y, et al. Combined T2-weighted and diffusion-weighted MRI for diagnosis of urinary bladder invasion in patients with prostate carcinoma. J Magn Reson Imaging. 2009;30:351-6.

37. Rockall AG, Ghosh S, Alexander-Sefre F, Babar S, Younis MT, Naz S, et al. Can MRI rule out bladder and rectal invasion in cervical cancer to help select patients for limited EUA? Gynecol Oncol. 2006;101:244-9. 


\section{Figure Legends}

Figure 1A. Disease Free survival (DFS)

Figure 1B. Distant, Local and Bladder recurrence

Figure 2. Bladder recurrence, depending on the presence of bladder invasion or not, and R1 or R0 margin 


\begin{tabular}{|c|c|c|c|c|c|c|c|c|c|c|c|}
\hline \multirow[b]{2}{*}{ Author } & \multirow[b]{2}{*}{ Inclusion } & \multirow[b]{2}{*}{$\mathbf{n}$} & \multirow{2}{*}{$\begin{array}{c}\text { cystectomies } \\
\text { Partial } \\
\text { Total }\end{array}$} & \multicolumn{2}{|c|}{$\begin{array}{c}\text { Pathological } \\
\text { results }\end{array}$} & \multicolumn{2}{|c|}{ Morbidity } & \multicolumn{4}{|c|}{ Oncological outcomes (5 years) } \\
\hline & & & & pT4b & $\begin{array}{l}\mathrm{R} 0 \\
\text { rate }\end{array}$ & Overall & Severe & OS & DFS & $\begin{array}{l}\text { Local } \\
\text { recurrence }\end{array}$ & $\begin{array}{l}\text { Bladder } \\
\text { recurrence }\end{array}$ \\
\hline Balbay & 1986-1996 & 81 & $\begin{array}{l}9 \\
46\end{array}$ & $60 \%$ & $94 \%$ & $29 \%$ & - & $55 \%$ & - & $17 \%$ & - \\
\hline Fujisawa & $1970-2001$ & 36 & $\begin{array}{l}19 \\
17\end{array}$ & - & - & $10 \%$ & - & $91 \%(3 y)$ & - & - & - \\
\hline Kobayashi & $1995-2000$ & 17 & $\begin{array}{l}12 \\
2\end{array}$ & $29 \%$ & - & - & - & - & - & - & - \\
\hline Carne & 1984-1999 & 53 & $\begin{array}{l}45 \\
4\end{array}$ & $39 \%$ & - & - & - & $75 \%$ & $55 \%$ & $16 \%$ & - \\
\hline Winter & $1985-2000$ & 63 & $\begin{array}{l}53 \\
10\end{array}$ & $54 \%$ & $89 \%$ & $18 \%$ & - & $57 \%$ & - & $14 \%$ & - \\
\hline Gao & $1995-2000$ & 33 & $\begin{array}{l}28 \\
5\end{array}$ & $45 \%$ & - & $33 \%$ & - & $39 \%$ & $30 \%$ & $27 \%$ & - \\
\hline $\mathbf{L i}$ & $1987-2004$ & 72 & $\begin{array}{l}58 \\
14\end{array}$ & $47 \%$ & - & $61 \%$ & - & $59 \%$ & $71 \%$ & $15 \%$ & - \\
\hline Luo & $2000-2011$ & 84 & $\begin{array}{l}84 \\
0\end{array}$ & $40 \%$ & - & - & - & - & - & - & $8.3 \%$ \\
\hline Hartwig & $1997-2012$ & 31 & $\begin{array}{l}16 \\
15\end{array}$ & $52 \%$ & $77 \%$ & $71 \%$ & $39 \%$ & $70 \%$ & - & $11 \%$ & $6.2 \%$ \\
\hline Nerli & 2001-2016 & 9 & $\begin{array}{l}8 \\
1\end{array}$ & $100 \%$ & $100 \%$ & - & - & - & - & - & - \\
\hline Yoshida & $2001-2015$ & 89 & $\begin{array}{l}49 \\
40\end{array}$ & $\begin{array}{l}39 \% \\
45 \%\end{array}$ & $100 \%$ & $\begin{array}{l}12 \% \\
50 \%\end{array}$ & - & $\begin{array}{l}70 \% \\
72 \%\end{array}$ & & $\begin{array}{l}37 \% \\
34 \%\end{array}$ & $8.2 \%$ \\
\hline Present study & 2010-2017 & 117 & $\begin{array}{l}108 \\
9\end{array}$ & $47 \%$ & $87 \%$ & $55 \%$ & $18 \%$ & $83 \%(3 y)$ & $\begin{array}{l}\mathbf{5 6 \%} \\
(3 \mathrm{y})\end{array}$ & $17 \%(3 y)$ & $10 \%$ \\
\hline
\end{tabular}

Table 1. Literature review on the prognosis and management of colonic cancer with bladder invasion 


\begin{tabular}{|c|c|}
\hline Characteristics & $\mathrm{n}(\%)$ \\
\hline$\overline{\text { Age }(\text { mean }+/- \text { SD) }}$ & $70.3+/-13.4$ \\
\hline Male & $73(62.4)$ \\
\hline BMI (mean +/- SD) & $25.1+/-4.4$ \\
\hline \multicolumn{2}{|l|}{ ASA $n(\%)$} \\
\hline $1 / 2$ & $15(12.8) / 57(48.7)$ \\
\hline $3 / 4$ & $33(28.2) / 1(0.8)$ \\
\hline Previous urological intervention (TURP, TURB, radical prostatectomy) & $10(8.5 \%)$ \\
\hline Previous hysterectomy & $6(13.6 \%)$ \\
\hline Left Colonic tumor & $110(94 \%)$ \\
\hline Urinary symptoms & $42(35.9)$ \\
\hline Urinary tract infection & $27(23.1)$ \\
\hline Dysuria & $17(14.5)$ \\
\hline Pneumaturia / Faecaluria & $17(14.5) / 13(11.1)$ \\
\hline Haematuria & $9(7.7)$ \\
\hline Pre-operative cystoscopy & $23(19.7)$ \\
\hline Macroscopic invasion & $15(65.2)$ \\
\hline Histologic invasion on biopsy & $5(21.7)$ \\
\hline Suspected bladder invasion (cT4) & $74(63.2)$ \\
\hline Suspected lymph node invasion (cN+) & $35(29.9)$ \\
\hline Neoadjuvant treatment & $31(26.5)$ \\
\hline Chemotherapy Alone & $22(71 \%)$ \\
\hline FOLFOX & 11 \\
\hline FOLFOX + Erbitux & 5 \\
\hline FOLFIRINOX & 6 \\
\hline Chemoradiotherapy $(45-50 \mathrm{~Gy}+5 \mathrm{FU})$ & $7(23 \%)$ \\
\hline Radiotherapy alone ( 45 or $25 \mathrm{~Gy}$ ) & $2(6 \%)$ \\
\hline Laparoscopic approach & $34(29.1)$ \\
\hline Conversion rate & $22(64.7)$ \\
\hline Left colectomy & $106(90.6)$ \\
\hline Right colectomy & $6(5.1)$ \\
\hline Subtotal colectomy & $5(4.3)$ \\
\hline Bowel anastomosis & $96(82.0)$ \\
\hline Loop ileostomy & $44(45.8)$ \\
\hline \multicolumn{2}{|l|}{ Location of bladder invasion } \\
\hline Apex & $84(71.8)$ \\
\hline Posterior side & $20(17.1)$ \\
\hline Uretero vesical junction & $11(9.4)$ \\
\hline Neck & $8(6.8)$ \\
\hline Total cystectomy and ileal conduit & $9(7.7)$ \\
\hline Partial cystectomy & $108(92.3)$ \\
\hline \multicolumn{2}{|l|}{ Type of reconstruction after partial bladder resection } \\
\hline Suture & $99(84.6)$ \\
\hline Enterocystoplasty & $3(2.6)$ \\
\hline Psoic bladder & $4(3.4)$ \\
\hline Unknown & $2(1.7)$ \\
\hline Associated procedures & $54(46.1)$ \\
\hline Small bowel resection & $22(40.7)$ \\
\hline Uterus and/or adnexa resection & $18(33.3)$ \\
\hline Vaginal cuff resection & $5(9.3)$ \\
\hline Segmental colectomy & $7(13.0)$ \\
\hline Abdominal wall resection & $7(13.0)$ \\
\hline Other (Epiploon, appendix, duodenum, vas deferens) & $8(14.8)$ \\
\hline
\end{tabular}


Table 2. Patient characteristics and surgical procedures. (TURP: Transuretral resection of the prostate, TURB: Transuretral resection of the bladder) 


\begin{tabular}{|c|c|}
\hline Characteristics & $\mathbf{N}(\%)$ \\
\hline Overall morbidity & $64(54.7)$ \\
\hline Clavien Dindo 1 & $11(9.4)$ \\
\hline Clavien Dindo 2 & $29(24.8)$ \\
\hline Clavien Dindo 3a & $3(2.6)$ \\
\hline Clavien Dindo 3b & $12(10.3)$ \\
\hline Clavien Dindo 4 & $6(5.1)$ \\
\hline Post-operative mortality (Clavien Dindo 5) & $3(2.6)$ \\
\hline Bowel anastomotic leak & $10(10.4)$ \\
\hline Peritonitis & $6(5.1)$ \\
\hline Surgical revision & $17(14.5)$ \\
\hline Urinary specific morbidity & $25(21.4)$ \\
\hline Bladder leak & $11(10.2)$ \\
\hline Postoperative urinary retention & $5(4.6)$ \\
\hline Ileal pouch related morbidity & $4(44.4)$ \\
\hline Length of stay (days) & $18.7+/-17.1$ \\
\hline \multicolumn{2}{|l|}{ Histological type } \\
\hline Lieberkuhnian adenocarcinoma & $93(79.5)$ \\
\hline Colloid & $22(18.8)$ \\
\hline Others & $6(5.2)$ \\
\hline \multicolumn{2}{|l|}{ Grade of differentiation } \\
\hline Low grade & $29(24.8)$ \\
\hline Intermediate grade & $58(49.6)$ \\
\hline High grade & $24(20.5)$ \\
\hline \multicolumn{2}{|l|}{ pT stage } \\
\hline pT1-pT2 & $2(1.7)$ \\
\hline pT3 & $37(31.6)$ \\
\hline pT4a & $13(11.1)$ \\
\hline pT $4 b$ & $65(55.6)$ \\
\hline Total lymph node count (mean +/- SD) & $24.4+/-11.4$ \\
\hline $\mathrm{pN}+$ & $34(29.1)$ \\
\hline Size of bladder resection (mm) & $45.8+/-22.2$ \\
\hline Pathological invasion of the bladder & $55(47.0)$ \\
\hline \multicolumn{2}{|l|}{ Depth of the bladder invasion } \\
\hline Peritoneum or fat tissue & $10(18.2)$ \\
\hline Detrusor muscle & $14(25.4)$ \\
\hline Urothelium & $12(21.8)$ \\
\hline Fistula & $13(22.2)$ \\
\hline Unknown & $6(10.9)$ \\
\hline R0 resection & $102(87.2)$ \\
\hline Invasion of bladder boundary & $7(6.0)$ \\
\hline Bladder margin $(\mathrm{mm})$ & $6.3+/-8.5$ \\
\hline TRG 1 & $4(12.9)$ \\
\hline TRG 2 & $9(29.0)$ \\
\hline TRG 3 & $7(22.6)$ \\
\hline TRG 4 & 0 \\
\hline MSI & $7(6.0)$ \\
\hline Adjuvant chemotherapy & $60(51.3)$ \\
\hline Folfox & $49(81.7)$ \\
\hline
\end{tabular}

Table 3. Post-operative course (30 days) and histologic features. 


\begin{tabular}{lccc}
\hline \multicolumn{1}{c}{ Variables } & $\begin{array}{c}\text { No local } \\
\text { recurrence }(\mathbf{n = 1 0 0})\end{array}$ & $\begin{array}{c}\text { Local recurrence } \\
(\mathbf{n = 1 7})\end{array}$ & $\mathbf{p}$ \\
\hline Age $>$ 65 years & $68(88)$ & $9(12)$ & 0.35 \\
Age $<$ 65 years & $32(80)$ & $8(20)$ & \\
Male & $63(86)$ & $10(14)$ & 0.95 \\
Female & $37(84)$ & $7(16)$ & \\
Partial cystectomy & $93(86)$ & $15(14)$ & 0.62 \\
Total cystectomy & $7(78)$ & $2(22)$ & \\
Bladder invasion & $44(80)$ & $11(20)$ & 0.19 \\
No bladder invasion & $56(90)$ & $6(10)$ & \\
R1 resection & $8(53)$ & $7(47)$ & $<0.001$ \\
R0 resection & $92(90)$ & $10(10)$ & \\
pN+ & $26(76)$ & $8(24)$ & 0.089 \\
pN0 & $74(89)$ & $9(11)$ & \\
Adjuvant chemotherapy & $51(85)$ & $9(15)$ & 1 \\
No adjuvant chemotherapy & $49(86)$ & $8(14)$ & \\
\hline
\end{tabular}

Table 4. Univariate analysis of local recurrence after colon cancer resection with bladder invasion. 


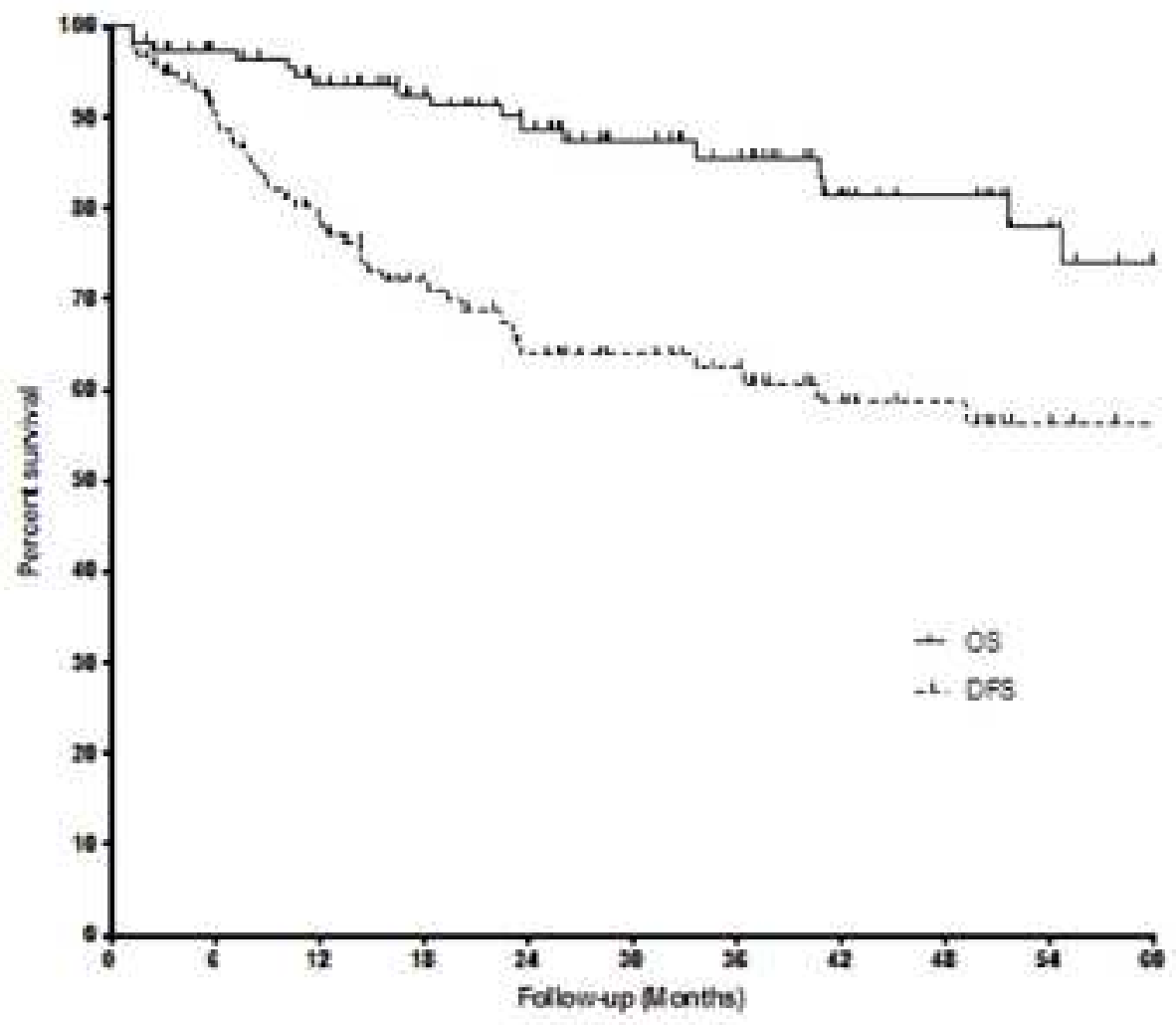

Figure 1A. Disease Free survival (DFS)

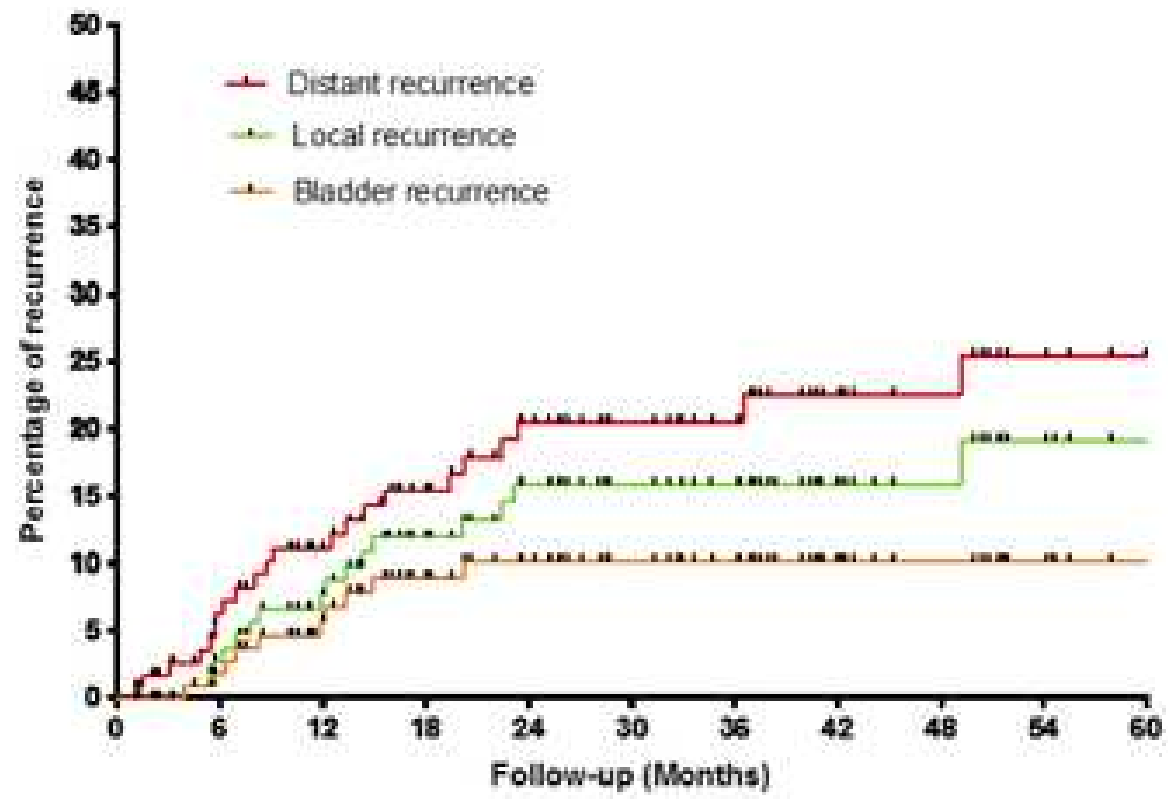

Figure 1B. Distant, Local and Bladder recurrence 


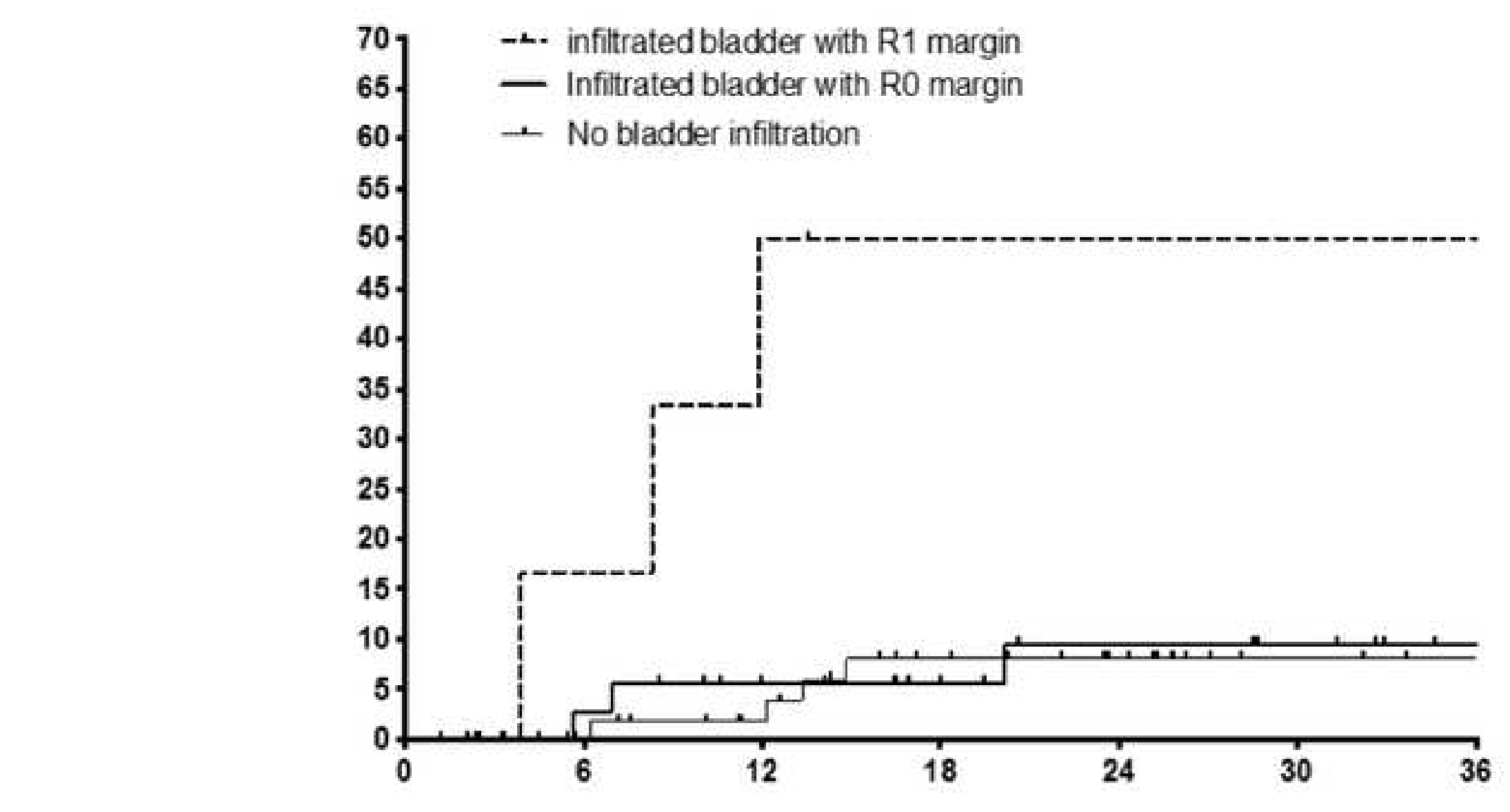

Figure 2. Bladder recurrence, depending on the presence of infiltration of the bladder or not, and R1 or R0 margin. or not, and R1 or R0 margin.

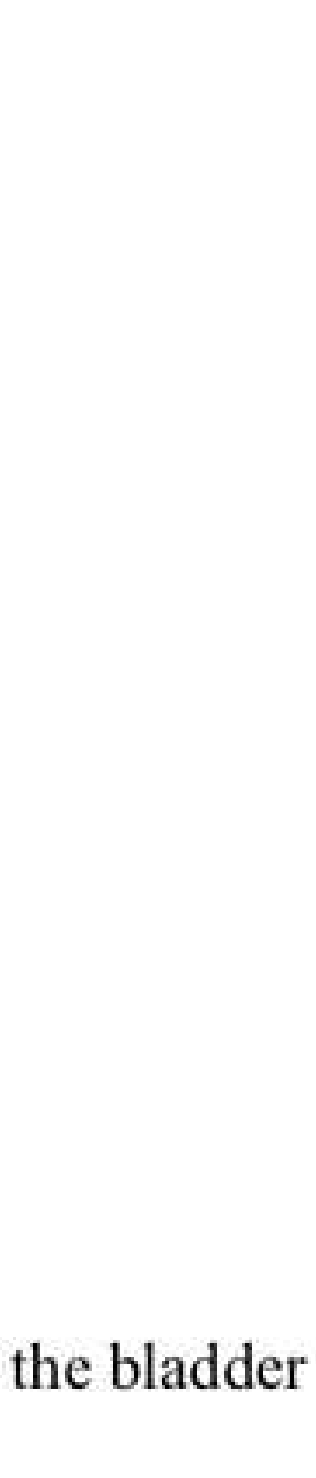


1. Please confirm that you have mentioned all organizations that funded your research in the Acknowledgements section of your submission, including grant numbers where appropriate. I confirm that I have mentioned all organizations that funded my research in the Acknowledgements section of my submission, including grant numbers where appropriate.

\section{REQUEST FOR ARTICLE SUMMARY}

Please provide two sentences; the first sentence should briefly summarize what you did or your findings (remember, one sentence). The second sentence should start out with "The importance of this (report or finding) is..." and then add your short justification to the end of this sentence. Please make this the same as your article summary in the manuscript, these two sentences should be verbatim in both places.

Clinical bladder invasion by colorectal cancer is at risk for local recurrence even without pathological bladder invasion and only an optimal surgery with R0 margins reduces LR.

The importance of this study is to show with a large cohort that a en-bloc partial cystectomy is sufficient in case of bladder invasion by a colorectal cancer.

3. AUTHORSHIP: In accordance with the ICMJE statement on authorship, "An 'author' is considered to be someone who has made substantive intellectual contributions to the published study. The ICMJE recommends that authorship be based on ALL of the following four criteria, NOT JUST ONE, TWO, OR THREE OF THESE CRITERIA: 1)Substantial contributions to the conception or design of the work; or the acquisition, analysis, or interpretation of data for the work 2)AND also drafting the work or revising it critically for important intellectual content; 3)AND final approval of the version to be published; 4)AND Agreement to be accountable for all aspects of the work in ensuring that questions related to the accuracy or integrity of any part of the work are

\section{Yes, I attest that each listed author meets the ICMJE criteria for authorship listed above}

4. COI/DISCLOSURE and FUNDING/SUPPORT: Every manuscript submitted to Surgery must contain an Acknowledgement section in which every listed author must disclose any financial AND direct or indirect personal relationships with other people or organizations that could potentially and inappropriately influence (bias) their work and conclusions. Examples of potential conflicts of interest include employment, consultancies, stock ownership, honoraria, paid expert testimony, patent applications/registrations, and research grants or other funding. The existence of competing interests is common and often inevitable. Competing interests are not inherently unethical, but not declaring them is. If no conflicts exist, the authors should state as such. Each disclosure needs its own statement labeled as such: COI/Disclosure: AND Funding/Support:.........

Yes, I have included both a COI/Disclosure Statement and a Funding/Support Statement just before the Reference section 
5. ACKNOWLEDGEMENTS: Please confirm that you have mentioned all organizations that funded your research in the Acknowledgements section of your submission, including grant numbers where appropriate. If there is no funding, specify that clearly. The Acknowledgements section should appear just before the Reference section.

\section{No. This is not applicable for me}

6. MANUSCRIPT: Please confirm that ALL authors have seen and approved both the primary submission or any revisions and the manuscript is not in press or submitted for consideration of publication elsewhere currently.

Yes, I confirm that all authors have seen and approved the manuscript and all correspondence with the journal and it is submitted only to SURGERY

7. PLAGIARISM: This submission contains no Plagiarism, meaning no direct reproduction of complete sentences or phrases of others published work or my own that are not referenced. Remember, with your own writing in the past, if the copyright is owned by another source (like a journal), you cannot copy and paste- THAT IS STILL PLAGIARISM.

Yes, I confirm that the manuscript contains no plagiarism of my past work or of other authors. Any direct wording has been identified and referenced

8. SUBJECTS: Use of any human subjects or animals has been approved by the institutional IRB or Animal Care committee and patient consent forms have been obtained whenever appropriate

Yes, I confirm that correct consent has been obtained if necessary

9. SEX OF SUBJECT: The sex of the human subjects, animals, cell cultures, tissue, etc. have been acknowledged in the methods section of the manuscript. If only one sex is studied, please provide a sentence explaining why only one sex was studied.

Yes, I confirm that the sex of the subject has been acknowledged in the methods section

10. CLINICAL TRIALS: If a clinical trial, the study has been registered at nih.gov or clinicaltrials.gov or some other national or international registry that is available to the public.

No. This is not applicable for me 